\title{
Antagonistic interaction between Trichoderma asperellum and Phytophthora capsici in vitro*
}

\author{
Heng JIANG ${ }^{1}$, Liang ZHANG ${ }^{1}$, Jing-ze ZHANG ${ }^{\dagger 1}$, Mohammad Reza OJAGHIAN ${ }^{1}$, Kevin D. HYDE ${ }^{2}$ \\ ('Institute of Biotechnology, College of Agriculture \& Biotechnology, Zhejiang University, Hangzhou 310058, China) \\ ( ${ }^{2}$ School of Science, Mae Fah Luang University, Chiang Rai 57100, Thailand) \\ 'E-mail: jzzhang@zju.edu.cn
}

Received Oct. 10, 2015; Revision accepted Dec. 10, 2015; Crosschecked Mar. 15, 2016

\begin{abstract}
Phytophthora capsici is a phytopathogen that causes a destructive pepper blight that is extremely difficult to control. Using a fungicide application against the disease is costly and relatively ineffective and there is also a huge environmental concern about the use of such chemicals. The genus Trichoderma has been known to have a potential biocontrol issue. In this paper we investigate the mechanism for causing the infection of $T$. asperellum against $P$. capsici. Trichoderma sp. (isolate CGMCC 6422) was developed to have a strong antagonistic action against hyphae of $P$. capsici through screening tests. The strain was identified as $T$. asperellum through using a combination of morphological characteristics and molecular data. $T$. asperellum was able to collapse the mycelium of the colonies of the pathogen through dual culture tests by breaking down the pathogenic hyphae into fragments. The scanning electron microscope showed that the hyphae of $T$. asperellum surrounded and penetrated the pathogens hyphae, resulting in hyphal collapse. The results show that seven days after inoculation, the hyphae of the pathogen were completely degraded in a dual culture. T. asperellum was also able to enter the $P$. capsici oospores through using oogonia and then developed hyphae and produced conidia, leading to the disintegration of the oogonia and oospores. Seven days after inoculation, an average $10.8 \%$ of the oospores were infected, but at this stage, the structures of oospores were still intact. Subsequently, the number of infected oospores increased and the oospores started to collapse. Forty-two days after inoculation, almost all the oospores were infected, with $9.3 \%$ of the structures of the oospores being intact and $90.7 \%$ of the oospores having collapsed.
\end{abstract}

Key words: Antagonism, Electron microscopy, Oogonium, Oospore, Pepper http://dx.doi.org/10.1631/jzus.B1500243

CLC number: S436.418

\section{Introduction}

Phytophthora blight is a major disease infecting pepper (Capsicum annuum) and cucurbit crops all over the world, caused by Phytophthora capsici (Erwin and Ribeiro, 1996; Fry and Goodwin, 1997). The pathogen causes not only root and crown rot of pepper,

\footnotetext{
¿ Corresponding author

* Project supported by the Special Fund for Agro-scientific Research in the Public Interest of China (No. 201503109) and the National Natural Science Foundation of China (No. 31571950)

(ii) ORCID: Jing-ze ZHANG, http://orcid.org/0000-0001-8604-8280

(C) Zhejiang University and Springer-Verlag Berlin Heidelberg 2016
}

but also aerial blight of the leaves, fruit, and stems. The survivals of sporangia, zoospores, and hyphae of $P$. capsici are short lived in fields, but its thick-walled oospores are durable and play a key role in the infectious life cycle, surviving under unfavorable conditions for long periods of time and serving as a dispersal propagule when established in the soil (McDonald and Linde, 2002; Do et al., 2012). Removing viable oospores from the field is therefore of great importance in the control of Phytophthora blight.

Oospores are regarded as the initial infection source for the disease and they are difficult to eradicate by regular use of fungicides; thus chemical 
control does not provide a satisfactory control mechanism. In addition, the extensive use of fungicides has resulted in the development of fungicide resistance in the $P$. capsici in pepper and cucurbits (Parra and Ristaino, 1998; Pennisi et al., 1998; Lamour and Hausbeck, 2000; Qi et al., 2012). Concern has been raised about the major environmental and toxicological hazards associated with the use of fungicides and thus alternative environmentally friendly methods are needed to control the disease (Kuhajek et al., 2003). Biocontrol alternatives have been found in the use of fungi antagonists, such as Trichoderma species. The Trichoderma species have been shown to be particularly effective in controlling phytopathogenic fungi and represent biocontrol agents that have been successfully used as biopesticides worldwide (Harman, 2006; Kaewchai et al., 2009). The Trichoderma species inhibit plant pathogens through one or more of the following mechanisms: mycoparasitism, competition for key nutrients and colonization sites, production of antibiotics (glyotoxins, viridine, trichodermine, furanone, 6-pentyl-pyrone, and so on), or stimulation of plant defense mechanisms (Benítez et al., 2004; Reino et al., 2008; Liu et al., 2009). Controlling chili blight, using Trichoderma sp. against $P$. capsici, has also been examined and the antagonistic isolates were screened. The Trichoderma species, such as $T$. harzianum, have excellent biocontrol potential (Sid Ahmed et al., 1999; 2003; Ezziyyani et al., 2007; Osorio-Hernandez et al., 2011). Despite ongoing trials to identify the significant biocontrol effects of using the Trichoderma species on hyphae of $P$. capsici, no study has proven that the Trichoderma species are able to infect the oospores of $P$. capsici. In addition, ultrastructural studies have been widely used to observe the mycosparasitism of Trichoderma spp. on coiling and penetration of hyphae in plant pathogens in the Ascomycete and Basidiomycete, but few studies have investigated this approach for Oomycetes (Elad, 1988; Benhamou and Chet, 1996; Gupta et al., 1999; Kexiang et al., 2002).

We screened isolates of Trichoderma to establish if any had a high biocontrol potential against $P$. capsici. One strain, Trichoderma sp. was isolated in the suburbs of Hangzhou City, China, which had strong antagonistic activity against hyphae and oospores of $P$. capsici. We identified this isolate, systematically observed its antagonistic activities and described its interactions between fungal hyphae and pathogenic oospores at the ultrastructural level. The results of this study are presented in this paper.

\section{Materials and methods}

\subsection{Pathogen isolation and oospore preparation}

The isolates of $P$. capsici were separated from the diseased roots of $C$. annuum cv. Hangxian No. 3 in the district of Hangzhou City, Zhejiang Province in March, 2011 and confirmed to be pathogenic by Kochs postulates. To produce oospores, the mating type of isolates was determined by co-inoculating potato dextrose agar (PDA) with the mycelial plugs of the testers provided by Ren-de QI (Institute of Plant Protection, Anhui Academy of Agricultural Sciences, China). All isolates obtained were identified as the A2 mating types

To obtain abundant oospores for performing assays, a pathogenic isolate (A2) and tester mating type A1 were co-inoculated in a PDA at $25{ }^{\circ} \mathrm{C}$ in darkness for $5 \mathrm{~d}$, and 5-mm culture discs were paired $5 \mathrm{~mm}$ apart in the center of the V8 juice agar medium (V8 juice (Campbell Soup Co., USA) $10 \%, \mathrm{CaCO}_{3}$ $0.1 \%$, and Agar $2 \%$ ), and then they were incubated at $20{ }^{\circ} \mathrm{C}$ in darkness. After $15 \mathrm{~d}$, the plates were incubated at $25^{\circ} \mathrm{C}$ in darkness for $45 \mathrm{~d}$.

\subsection{Isolation and screening of antagonistic isolates}

Strains of Trichoderma were isolated from the soil surrounding the roots of diseased C. anпиит cv. Hangxian No. 3 in the suburbs of Hangzhou City, Zhejiang Province, China, which is in an area where yearly outbreaks of pepper blight occur. Fungal isolates were grown on PDA at $25{ }^{\circ} \mathrm{C}$ in darkness for conidial production and purification was classically achieved through the isolation of a single spore (Chomnunti et al., 2014).

The antagonistic isolates were screened using the dual culture method. Mycelial discs (5-mm diameter) from Trichoderma isolates and the pathogen isolate were placed $6 \mathrm{~cm}$ apart on the same PDA plate $(9 \mathrm{~mm})$ and all plates were incubated for one week at $25^{\circ} \mathrm{C}$ in darkness. All tests were carried out using five replicates. The growths of the pathogen and Trichoderma isolates were observed and their antagonistic activities were evaluated based on the antagonism 
scale from class 1 to class 5 (Bell et al., 1982). Calss 1: Trichoderma $\mathrm{sp}$. grew completely on the pathogen and covered the whole surface of the culture medium; class 2: Trichoderma sp. grew on at least two-thirds of the culture medium; class 3: each Trichoderma sp. and the pathogen colonized nearly half of the culture medium and no organism dominated the other; class 4 : at least two-thirds of the culture medium was colonized by the pathogen and the pathogen resisted encroachment of the antagonist; class 5: the pathogen grew completely on the Trichoderma sp. and colonized the whole surface of the culture medium.

\subsection{Fungal identification}

The Trichoderma isolate with highest antagonistic activity against $P$. capsici was identified using morphological characteristics and molecular data using phylogenetic analyses (Jaklitsch, 2009; 2011). The colony appearance and sporulation patterns were recorded from cultures grown on PDA or cornmeal dextrose agar (CMD) at $25{ }^{\circ} \mathrm{C}$ in darkness. The morphological characteristics were captured using a Zeiss Axiophot 2 microscope with Axiocam CCD camera and Axiovision digital imaging software (AxioVision Software Release 3.1, Version 3-2002; Carl Zeiss Vision Imaging Systems).

DNA extraction, polymerase chain reaction (PCR) amplifications, and sequencing for Trichoderma strains were conducted as described by Zhang and $\mathrm{Li}$ (2009). Mycelial disks were excised from the margins of the colonies and inoculated in $100 \mathrm{ml}$ of liquid growth media (potato dextrose broth, PDB) in $250 \mathrm{ml}$ flasks, shaken at $200 \mathrm{r} / \mathrm{min}$ at $25{ }^{\circ} \mathrm{C}$ for $4-5 \mathrm{~d}$. Mycelia were then harvested by filtration, freeze-dried, ground to a fine powder in liquid nitrogen, and then were placed into a $1.5-\mathrm{ml}$ tube, rehydrated in $600 \mu \mathrm{l}$ of $2 \times$ cetyltrimethyl ammonium bromide (CTAB) buffer $(100 \mathrm{mmol} / \mathrm{L}$ Tris, $\mathrm{pH} 8.0,1.4 \mathrm{~mol} / \mathrm{L} \mathrm{NaCl}, 30 \mathrm{mmol} / \mathrm{L}$ ethylene diamine tetraacetic acid (EDTA), $2 \%$ hexadecyltri-methylammonium bromide), and incubated in a water bath at $65^{\circ} \mathrm{C}$ for $60 \mathrm{~min}$. Following a phenol/chloroform extraction, the genomic DNA was precipitated by isopropanol in the presence of sodium acetate and visualized in $1 \%(0.01 \mathrm{~g} / \mathrm{ml})$ agarose gels after ethidium bromide staining.

The ITS region was amplified by PCR using universal primers ITS6 (5'-GAAGGTGAAGTCGT AACAAGG-3') and ITS4 (5'-TCCTCCGCTTATTG
ATATGC-3') (White et al., 1990). A fragment of the translation elongation factor $1 \alpha(t e f 1)$ gene was amplified using primers EF1-728F (5'-CATCGAGAA GTTCGAGAAGG-3') (Carbone and Kohn, 1999) and TEf1-R (5'-GCTGGTATCTCCAAGGATGGC-3') (Kullnig-Gradinger et al., 2002). A fragment of the RNA polymerase II subunit B ( $r p b 2$ ) was amplified using the primer pair fRPB2-5f (5'-GAYGAYMG WGATCAYTTYGG-3') and fRPB2-7cr (5'-CCCAT RGCTTGTYYRCCCAT-3') (Liu et al., 1999). The PCR amplifications were performed in a thermal cycler using the following parameters: $3 \mathrm{~min}$ initial denaturation at $94{ }^{\circ} \mathrm{C}$, followed by 35 cycles of $60 \mathrm{~s}$ denaturation at $94{ }^{\circ} \mathrm{C}, 1 \mathrm{~min}$ primer annealing at $51^{\circ} \mathrm{C}, 60 \mathrm{~s}$ extension at $72{ }^{\circ} \mathrm{C}$, and a final extension period of $7 \mathrm{~min}$ at $72{ }^{\circ} \mathrm{C}$. Each PCR product was electrophoresed in $1 \%(0.01 \mathrm{~g} / \mathrm{ml})$ agarose gels. After purification, the PCR product was sequenced in both directions.

To identify isolates of Trichoderma spp., sequences of ITS, tefl, and $r p b 2$ were analyzed by the TrichOKey (Druzhinina et al., 2005), TrichoBLAST (Kopchinskiy et al., 2005), and the National Center for Biotechnology Information (NCBI) Nucleotide BLAST Search. Novel sequences, together with reference sequences obtained from the GenBank, were aligned using Clustal X (Thompson et al., 1997). Caution was used in the selection of reference sequences from the GenBank, with only those being selected from type or voucher specimens. Datasets, namely the ITS/5.8S ribosomal DNA (rDNA) dataset and combined partial tefl and $r p b 2$ gene datasets, were analyzed by using a maximum parsimony as implemented in PAUP* 4.0b10 (Sinauer Associates, Inc., Sunderland, MA, USA).

\subsection{Antagonism of Trichoderma strains against a pathogen hyphae}

The antagonistic mechanisms of T. asperellum against hyphae of $P$. capsici were observed by light microscopy and scanning electron microscopy (SEM). After a colony of $T$. asperellum contacted that of pathogen on PDA in a dual culture, interactive zones of hyphae from different time periods were cut into pieces, which were then observed directly under a light microscope or were used for SEM study.

Fixing using $3 \mathrm{~mm} \times 4 \mathrm{~mm}$ pieces was performed in $2 \%$ glutaraldehyde in a $0.2 \mathrm{~mol} / \mathrm{L}$ phosphate buffer 
(pH 6.8-7) for $7-8 \mathrm{~h}$ at $24-26{ }^{\circ} \mathrm{C}$. Afterwards, the samples were washed with $0.2 \mathrm{~mol} / \mathrm{L}$ phosphate

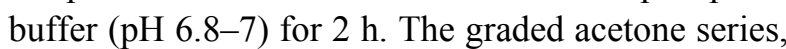
consisting of $30 \%, 50 \%, 70 \%, 80 \%, 90 \%$, and $100 \%$, were used to dehydrate the samples. The samples were dehydrated in each grade for 30-45 min and also three times for the acetone grade $100 \%$. After samples were completely dehydrated, they were dried using a drier (HCP-2, Hitachi). After mounting the samples on stubs, gold (200-nm thickness) was used to coat the samples in a sputter coater (JFC-1600, JEOL). Finally, SEM (JSM-6360LV, JEOL Ltd.) was used to examine the coated samples at $10 \mathrm{kV}$.

\subsection{Antagonism of Trichoderma strain against oospores}

After pathogenic isolate 01 (A2) and tester mating type $\mathrm{A} 1$ were incubated in a $\mathrm{V} 8$ juice medium for two months as described above, a dense oospore zone was cut into pieces $(1 \mathrm{~cm} \times 1 \mathrm{~cm})$. In a plate containing fresh PDA, 4 pieces $(1 \mathrm{~cm} \times 1 \mathrm{~cm})$, which were $2 \mathrm{~cm}$ from the center of the plate on cross direction, were removed and then pieces (with the same size) containing oospores were placed into the same position. A disc (diameter $5 \mathrm{~mm}$ ) containing mycelium of antagonistic isolate of $T$. asperellum was inoculated into the center of the plate. The plate was incubated at $25{ }^{\circ} \mathrm{C}$ in darkness. After the hyphae contacted the oospores, pieces were cut from the oospore zones at 5,10,15,20, and $40 \mathrm{~d}$ for light and electron microscopy observation.

The light microscopy was used to estimate degree of antagonism against the oospores in different time periods. Excess agar was removed from the pieces containing oospore and the pieces were stained with $1 \%$ aniline blue solution for $5 \mathrm{~min}$, and then mounted on slides and examined with a microscope under oil immersion. The tests were carried out in five replicates and at least 500 oospores were observed. The degree of antagonism against the oospores was divided into three types, including the infected oogonia, infected oospores, and collapsed oospores (Fig. 1). Infected oogonium: the oogonium was penetrated by the hyphae of the antagonist and the periplasm was stained with blue, but the oospore was not infected (without staining). Infected oospore: the oospore was infected (stained blue) and it became abnormal or disintegrated within an oogonium. Col- lapsed oospores: the oognium and oospore were degraded into fragments which contained hyphae and conidia among them. During each time period, infected oogonia, infected oospores, and collapsed oospores were counted using the formula: $N_{\text {uni }}=N_{\text {tot }}{ }^{-}$ $\left(N_{1}+N_{2}+N_{3}\right)$, where $N_{\text {uni }}$ is the number of uninfected oogonia and oospores; $N_{\text {tot }}$ is the total number of oospores examined; $N_{1}, N_{2}$, and $N_{3}$ are the numbers of infected oogonia, infected oospores, and collapsed oospores, respectively. The analysis of the variance in a completely randomized design test was performed using SPSS (Version 17, Chicago, IL, USA).
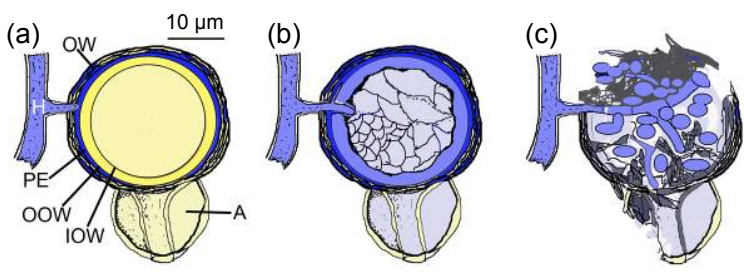

Fig. 1 Schematic drawing of infection of oogonium and oospores of Phytophthora capsici by hyphae of Trchoderma sp. (a) Infected oogonium. The hyphae penetrate oogonial wall (OW) to invade periplasm (PE) and oospore is not infected. Hyphae, partial OW, and hyphae are shown in blue. A: antheridium; OOW: outer oospore wall; IOW: inner oospore wall. (b) Infected oospore. The hyphae penetrate the outer and inner walls of oospore and ooplasts are abnormal or are disintegrated within an oogonium. Hyphae, partial OW, and oospore are shown in blue. (c) Collapsed oospore. Hyphae and conidia are shown in blue (Note: for interpretation of the references to color in this figure legend, the reader is referred to the web version of this article)

Using transmission electron microscopy, the ultrastructural characteristics of the interaction between the antagonist and oospores were observed. The pieces (approximately $1 \mathrm{~mm} \times 2 \mathrm{~mm}^{2}$ ) containing dense oospores were placed in $2.5 \%$ glutaraldehyde in a $0.1 \mathrm{~mol} / \mathrm{L}$ sodium phosphate buffer ( $\mathrm{pH} 7.0)$ for $18 \mathrm{~h}$ at $4{ }^{\circ} \mathrm{C}$. The same buffer was used to wash each of the samples six times. The samples were post-fixed with $1 \%(0.01 \mathrm{~g} / \mathrm{ml})$ osmium tetroxide in the same buffer for $2-3 \mathrm{~h}$ at $22^{\circ} \mathrm{C}$.

The samples were completely washed with a $0.2 \mathrm{~mol} / \mathrm{L}$ phosphate buffer ( $\mathrm{pH} 6.8$ ), and dehydrated using a graded series of ethanol. Pieces were embedded in Spurr's epoxy resin. Light microscopy was used to identify the sites containing oospores. A Reichert-Jung UltracutE ultramicrotome with a diamond knife was used to cut the ultrathin sections. The 
ultrathin pieces were collected using formvar-coated slot copper grids. After drying, the grids were stained with uranyl acetate and lead citrate. Lastly a transmission electron microscope with a Gatan 832 CCD camera (Hitachi H-7650, Tokyo, Japan) was used to examine the grids at $80 \mathrm{kV}$.

\section{Results}

\subsection{Screening for antagonistic isolates}

Of the 62 Trichoderma isolates screened, the antagonism was only slightly apparent or not at all when compared to $P$. capsici for $80 \%$ of Trichoderma (antagonism class for 3-5) and was very apparent for $13.5 \%$ (antagonism class for 2). Four isolates (antagonism class for 1) showed a strong activity against the hyphae of $P$. capsici, while the isolate CGMCC 6422 displayed the greatest activity and it was deposited in the China General Microbiological Culture Collection Center (CGMCC) and culture collections of the Institute of Biotechnology, College of Agriculture and Biotechnology, Zhejiang University, China.

\subsection{Identification of antagonistic isolates}

Based on morphological characteristics of conidia, conidiophores, phialides, and chlamydospores on CMD, the isolate Trichoderma sp. CGMCC 6422 was identified as T. asperellum, as described in the Trichoderma Home (http://nt.ars-grin.gov/taxadescriptions/ keys/TrichodermaIndex.cfm). TrichOKey, TrichoBLAST and the NCBI Nucleotide BLAST Search also showed that isolate CGMCC 6422 was related closely to $T$. asperellum. Phylogenetic analysis showed that isolate Trichoderma CGMCC 6422 clustered together with the reference isolate GJS907 of T. asperellum, with $100 \%$ bootstrap support (Fig. 2). A combination of morphological and molecular data clearly indicated that isolate Trichoderma CGMCC 6422 is the same species as T. asperellum.

\subsection{Antagonism of Trichoderma isolate CGMCC 6422 against hyphae of $P$. capsici}

The antagonism of $T$. asperellum (strain CGMCC 6422) against $P$. capsici was observed further in dual culture. After $40 \mathrm{~h}$ following inoculation, the hyphae of $T$. asperellum had outgrown the colony margin of

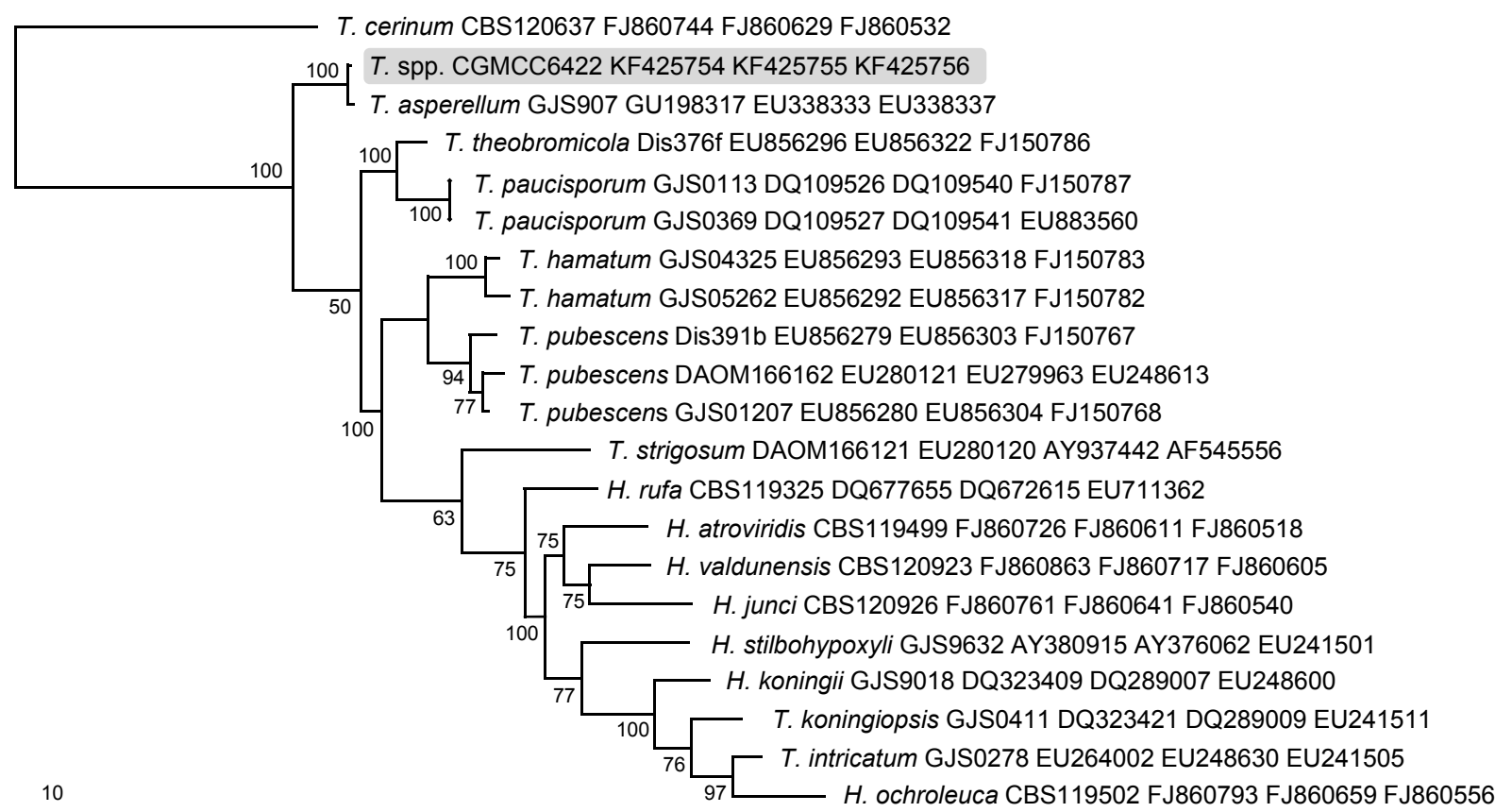

Fig. 2 Parsimonious tree based on combined ITS, tef1, and rpb2 sequences

Data are analyzed with random addition sequence, unweighted parsimony and treating gaps as missing data. Bootstrap values $\geq 50 \%$ are shown above or below branches. Each taxon contains isolate No. and GenBank accession No. (ITS, tef1, and rpb2). The tree is rooted with Trichoderma cerinum 
P. capsici and caused partial mycelial collapse (Fig. 3a). In light micrographs, hyphae of $P$. capsici were degraded into fragments (Fig. 3b). SEM observation revealed two modes of antagonism by $T$. asperellum against $P$. capsici. After contact, hyphae of $T$. asperellum formed dense coils and tightly encircled the hyphae of $P$. capsici (Fig. 3c). At this stage, the hyphae of $P$. capsici were intact (Fig. 3c). Hyphae of $T$. asperellum surrounding the hyphae of $P$. capsici caused a wrinkled appearance or caused the hyphae to collapse (Fig. 3f). In another mode, hyphal apices of $T$. asperellum came into contact and penetrated the hyphae of $P$. capsici, resulting in hyphal collapse (Figs. 3d and $3 \mathrm{e})$. Seven days after inoculation, colonies of $P$. capsici were disintegrated completely and numerous conidia of T. asperellum were produced (Fig. 3g).
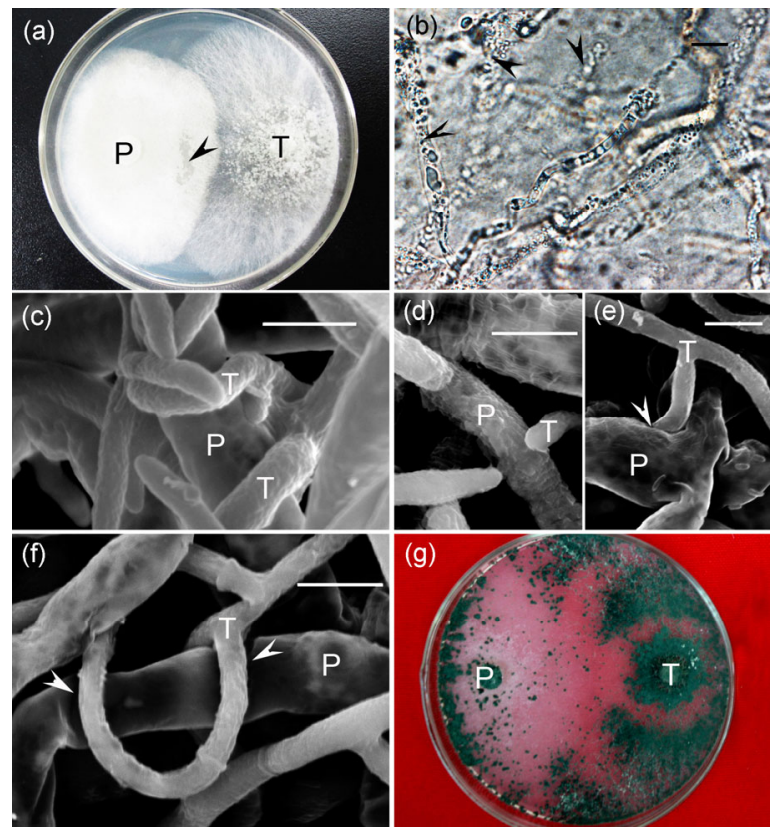

Fig. 3 Antagonism of Trichoderma asperellum CGMCC 6422 against Phytophthora capsici 01

(a) The collapsed region (arrowhead) after hyphae of $T$. asperellum (T) overgrowing the colony margin of $P$. capsici (P). (b) Hyphae of P. capsici being damaged into fragments (arrowhead) in the collapsed region of (a) under light microscope $48 \mathrm{~h}$ after innoculation. Bar=10 $\mu \mathrm{m}$. (c)-(f) Scanning electron micrographs of hyphae of $T$. asperellum interacting with hyphae of $P$. capsici. (c) Hyphae of T. asperellum arounding those of $P$. capsici tightly. Bar $=5 \mu \mathrm{m}$. (d) Hyphal apexes of $T$. asperellum contacting with or penetrating hyphae of $P$. capsici. Bar $=5 \mu \mathrm{m}$. (e) Hypha of $T$. asperellum invading into hyphae of $P$. capsici. Note that infection site (arrowhead) is depressed significantly. Bar=5 $\mu \mathrm{m}$. (f) Hyphae of $T$. asperellum encircling those of $P$. capsici. Note that hyphae of $T$. asperellum cause those of $P$. capsici to collapse (arrowhead). Bar $=5 \mu \mathrm{m}$. (g) Colony of $P$. capsici being damaged completely by $T$. asperellum $7 \mathrm{~d}$ after innoculation

\subsection{Antagonism of $T$. asperellum against oospores of $P$. capsici}

The hyphae of $T$. asperellum could infect oospores of $P$. capsici and cause oospores to finally disintegrate. In the process of infection, fungal hyphae first penetrated the oogonia to go into the periplasms that were stained blue seven days after inoculation (Fig. 4a), apparently the purple-yellowish oospores were not infected. Occasionally, oospores infected by $T$. asperellum also were found and stained blue with irregularly waved inner walls (Fig. 3a), but the oospore structures were intact with abnormal or disintegrated ooplast within an oogonium. Twelve days after inoculation, the oospores collapsed (Fig. 4b). At this stage, it was difficult to observe fungal hyphae and conidia. Subsequently, the oospores were broken into small fragments surrounded by partially ruptured walls of oogonia and fungal hyphae and rounded conidia developed (Fig. 4c). With the increase in the number of collapsed oospores, the cracked oogonia were also completely disintegrated (Figs. 4d and 4e).

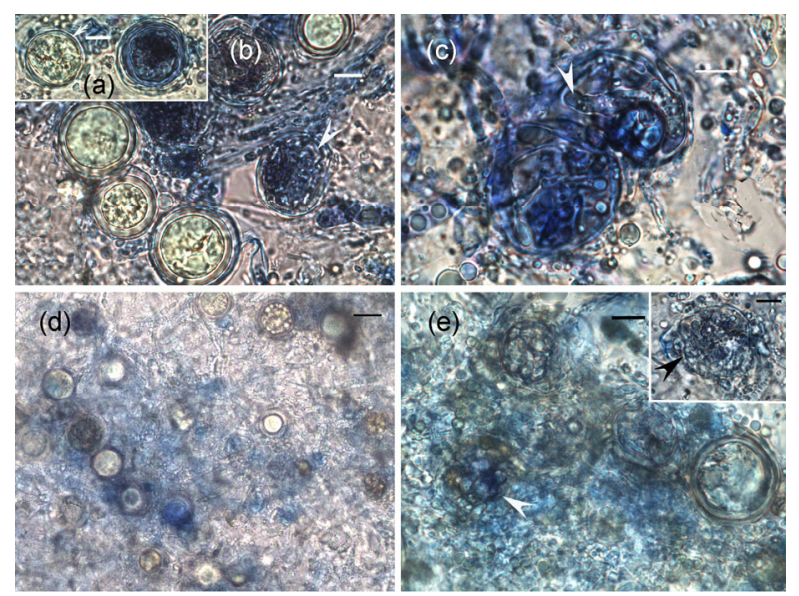

Fig. 4 Hyperparasitism of Phytophthora capsici oospores by Trichoderma asperellum CGMCC 6422

(a) A damaged oospore stained blue (right) $7 \mathrm{~d}$ after inoculation. Note that an undamaged oospore (left) contains blue dye (arrow) between an oogonium and an oospore. Bar $=10 \mu \mathrm{m}$. (b) The damaged oospores (arrowhead) stained blue $12 \mathrm{~d}$ after inoculation. The uninfected oospores show yellowish, with intact structure. Bar $=10 \mu \mathrm{m}$. (c) The damaged oospores containing hyphae of T. asperellum $17 \mathrm{~d}$ after inoculation. Bar $=10 \mu \mathrm{m}$. (d) A lot of undamaged and damaged oospores $22 \mathrm{~d}$ after inoculation. Bar $=20 \mu \mathrm{m}$. (e) Completely damaged oospores with fungal conidia (arrowheads) $22 \mathrm{~d}$ after inoculation. Bar $=10 \mu \mathrm{m}$ (Note: for interpretation of the references to color in this figure legend, the reader is referred to the web version of this article) 
In the process of infection of the oospores by $T$. asperellum, the numbers of infected oogonia, infected oospores, and collapsed oospores changed with time, as shown in Fig. 5. Seven days after inoculation, $10.8 \%$ of the oogonia and few oospores $(2.1 \%)$ were infected but no collapsed oospores were found. Most of the oogonia and oospores $(87.2 \%)$ were not infected. Twelve days after inoculation, fungal hyphal development and conidia, which were produced within the oogonia, caused the oospores to collapse and the number of collapsed oospores $(21.8 \%)$ increased significantly $(P<0.05)$. The number of infected oogonia (13.6\%) and infected oospores $(10.0 \%)$ also increased significantly. At this stage, almost half of the oogonia and oospores (45.4\%) were uninfected. After $17 \mathrm{~d}$, the number of collapsed oospores increased significantly and reached $45.4 \%$. During this period, the hyphae of $T$. asperellum produced numerous conidia within the collapsed oospores with or without cracked oogonia. After $22 \mathrm{~d}, 78.2 \%$ of the oogonia and oospores were infected and among them, the number of collapsed oospores reached $51.6 \%$ but for the period from 17 to $22 \mathrm{~d}$, the differences in the percentage of infected oogonia and oospores were not significant $(P<0.05)$. By $42 \mathrm{~d}$, almost all of the oogonia and oospores were infected and among them, an overwhelming majority of oospores were completely broken into fragments.

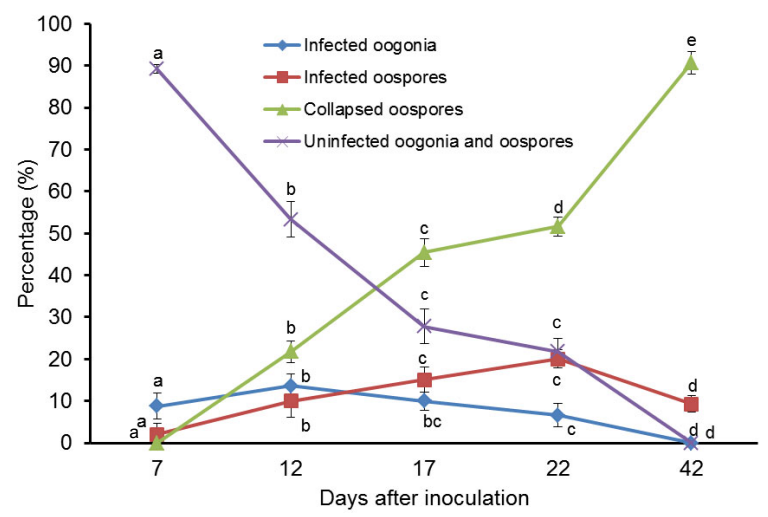

Fig. 5 Percentages of undamaged and damaged oospores after $7,12,17,22$, and $42 \mathrm{~d}$

Degree of infection of the oospores by $T$. asperellum is compared by the number of infected oogonia $\left(N_{1}\right)$, infected oospores $\left(N_{2}\right)$, collapsed oospores $\left(N_{3}\right)$, and uninfected oogonia and oospores $\left(N_{\text {uni }}\right)$ at different time points. Data are expressed as mean $\pm \mathrm{SD}$ with different letters indicating a significant difference at different time points according to Fisher LSD test $(P<0.05)$

\subsection{Interaction between antagonistic hyphae and oospores}

Transmission electron micrographs revealed the mechanism of interaction between the hyphae of $T$. asperellum and the oospores of $P$. capsici. The hyphae of $T$. asperellum penetrated the oogonium to form a small hyphal cluster between the oogonium and oospore (Figs. 6a and $6 \mathrm{~b}$ ). In some cases, there was no significant change in the hyphal diameters when penetrating the oogonium wall, but the hyphae caused the oogonial wall to rupture (Fig. 6b). However, in other cases, the hyphae became very narrow when penetrating the oogonium wall and the fungal hyphae of $T$. asperellum were in close contact with the oogonium walls (Fig. 6g).

At the same stage of development (twelve days after inoculation), a normal mature oospore with an oogonium developed about a $0.1-\mu \mathrm{m}$ thick electrondense outer wall and a 4.0-4.5- $\mu \mathrm{m}$ thick electrontransparent inner wall (Fig. 6h). The oogonial wall was electron-dense, $0.45 \mu \mathrm{m}$ thick, and the periplast between the wall of the oogonium and outer wall of the oospores disappeared or shrunk to a few electronopaque small residual bodies. The ooplast vacuoles with fewer granules were electron-transparent and scattered in a uniform cytoplasm (Fig. 6h). However, among the oospores infected by hyphae of $T$. asperellum, almost all oospores first disintegrated and then the most striking characteristic was that the contents surrounded by an outer oospore wall were homogeneous and electron-transparent (Figs. 6a, 6c, and 6e). Apparently, the oospores which had become infected died at this stage because the differences between the oospore wall and cytoplasms were not distinguishable. After the hyphae of $T$. asperellum had penetrated an oogonium, numerous hyphae propagated between the oogonium and the oospore, and some hyphae were in close contact with the outer wall of the oospore, resulting in its outer wall becoming deeply invaginated (Figs. $6 \mathrm{c}$ and $6 \mathrm{~d}$ ). When a large number of the hyphae filled the space between the oogonium and oospore, this caused the outer wall of the oospores to severely invaginate. Meanwhile, the outer walls of the oospores were apparently degraded (Figs. 6e and 6f). Finally, the oogonia and oospores were completely disintegrated (data not shown). This is the first reported mechanism of the interaction between the hyphae of T. asperellum and the oospore of $P$. capsici at the ultrastructural level. 

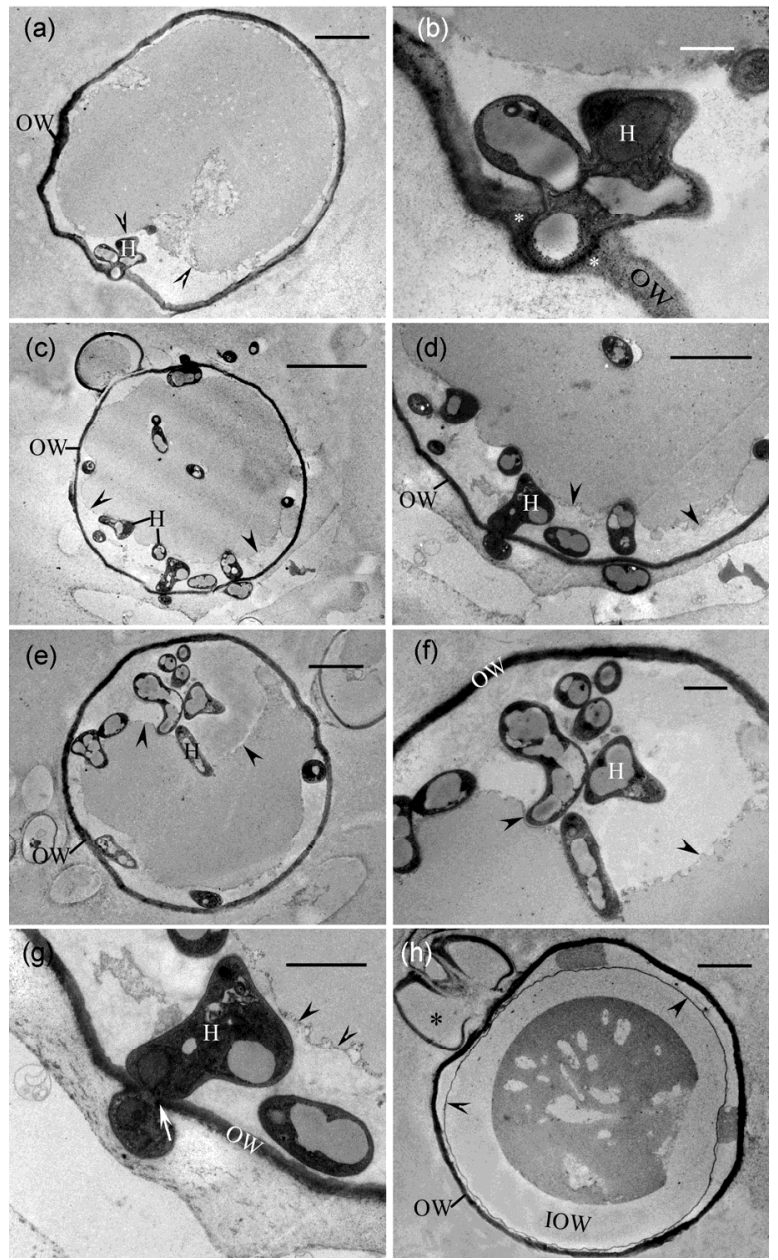

Fig. 6 Transmission electron micrographs of the interaction between oospores of Phytophthora capsici and Trichoderma asperellum CGMCC 6422

(a) Oospore infected by hyphae $(\mathrm{H})$ of $T$. asperellum. Oogonial wall (OW) is penetrated by hyphae of $T$. asperellum and a few hyphae form a hyphal cluster between oogonium and oospore walls (arrowheads). Note that entire contents of the oospore are homogeneous and electron-transparent. Bar $=5 \mu \mathrm{m}$. (b) Magnified view of an oospore in (a). A hyphal cluster. Note that hyphae at infected site cause oogonial wall to rupture $(*)$. Bar $=1 \mu \mathrm{m}$. (c) Longitudinal section of an oospore containing a lot of hyphae. The hyphae are distributed between oogonium and oospore walls (arrowheads) and within oospore. Bar $=10 \mu \mathrm{m}$. (d) Magnified view of an oospore in (c). The invaginated outer wall (arrowheads) of an oospore within an oogonium contacts closely with the walls of hyphae. Bar $=5 \mu \mathrm{m}$. (e) Transverse section of an oospore containing a lot of hyphae. The hyphae cause outer wall of an oospore to invaginate severely. Bar $=5 \mu \mathrm{m}$. (f) Magnified view of an oospore in (e). Severely invaginated outer wall (arrowheads) is degraded by closely contacted hyphae. Bar $=2 \mu \mathrm{m}$. (g) Magnified view of an oospore in (c). A hypha within an oogonium become narrow (arrow) in process of penetrating the oogonial wall. Bar $=2 \mu \mathrm{m}$. (h) Longitudinal section of an oospore with normal development. A mature oospore has an electron-dense outer oospore wall (arrowheads) and an electron-transparent inner oospore wall (IOW) within an oogonium with amphigynous antheridium $\left({ }^{*}\right)$. Bar $=5 \mu \mathrm{m}$

\section{Discussion}

The species of the genus Trichoderma are ubiquitous in the environment and especially in the soil. Several species of Trichoderma have been shown to be particularly effective in the control of $P$. capsici, and are used as biocontrol agents for controlling pepper blight (Sid Ahmed et al., 1999; 2003; Ezziyyani et al., 2007; Osorio-Hernandez et al., 2011). However, it is unclear whether these fungi also have antagonistic activities against the oospores of $P$. capsici. Our results first demonstrated that isolates of T. asperellum with antagonistic activities against the hyphae of $P$. capsici were also able to infect the oospores of $P$. capsici. This reveals a new application potential of Trichoderma spp. for controlling Phytophthora blight in fields with oospore colonization.

Oospores of $P$. capsici play a key role in overwintering and as the source of a primary infection. The percentage of oospore germination was used as an evaluation indicator for estimating the survival of oospores in soils. However, some studies showed that the ratio of oospore germination in the case of $P$. capsici (heterothallic) was very low, ranging from 0 to 51\% (Satour and Butler, 1968; Ribeiro et al., 1975; Boccas, 1981; Papavizas et al., 1981; Hord and Ristaino, 1991). The ratio of low germination maybe attributed to some complicated reasons, such as oospore dormancy and abnormal development (Etxeberria et al., 2011). Assuredly, our observations indicated that almost all oospores were fully developed in more than two and a half months, as described by Hemmes and Bartnicki-Garcia (1975), but ultrastructural observations indicated that a few oospores were abortive during the process of their development (Figs. 7a and 7b). These oospores within the oogonia became smaller in size and the oogonial walls were relatively thin, leading to large spaces between an oospore and an oogonium. Apparently, they were abnormal compared with fully developed oospores (Fig. 6h). Although in this stage the hyphae of $T$. asperellum infected oospores and also caused the oospores to be malformed or entire oospores to be degraded (Figs. 7c and 7d), the oospores occupied most of space within the oogonium and their oogonial walls were distinctly thick, being the same as that of a fully developed oogonium. Therefore, our results imply that the abortive oospores possibly contribute to the low germination ratio of oospores. 

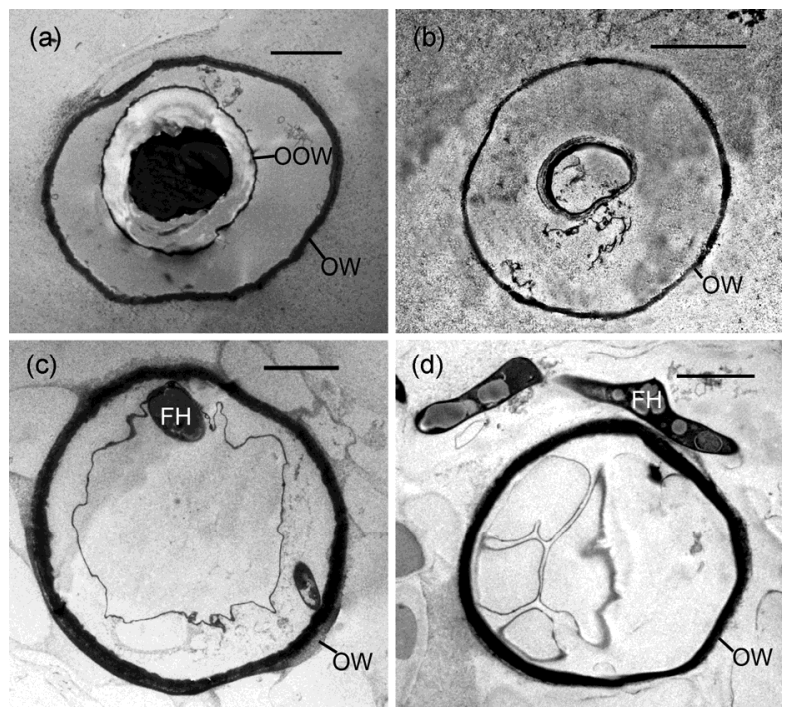

Fig. 7 Malformed oospores

(a, b) Aborted oospores with relatively thin oogonial walls. (a) A shrunken oospore within an oogonium. (b) A severely shrunk oospore within an oogonium. (c) An oospore with malformed outer wall and fungal hypha. (d) A degraded oospore with an oogonium. OW: oogonial wall; OOW: outer oospore wall; FH: fungal hypha. $\mathrm{Bar}=5 \mu \mathrm{m}$

Evaluation of a number of infected and collapsed oospores is essential to screen biocontrol isolates with highly antagonistic activity. Although electron microscopy provides the fine details of ultrastructural characteristics for our understanding of the interaction between oospores and the hyphae of $T$. asperellum, it is not suitable for a lot of sample observation due to its time-consuming process and high costs. A convenient staining method was established for observing infected and degraded oospores by light microscopy. Oospores without infection could not be stained by aniline blue. After an oogonium was penetrated by the hyphae of $T$. asperellum, the space with or without less periplast between oogonium and oospore walls was filled by blue dye but the oospore was not stained. When an oospore was infected, the entire oospore took on a blue color within an oogonium. With fungal development, a few hyphae could be found within a collapsed oospore. Finally, oogonia and oospores were disintegrated into fragments containing fungal hyphae and conidia. So this method can be used effectively for estimating the degree of antagonism against oospores, but in principle, it is not different from the determination of viability of $P$. capsici oospores with the tetrazolium bromide staining and plasmolysis method (Etxeberria et al., 2011).
In conclusion, our results display a huge potential for T. asperellum isolate CGMCC 6422 as valuable biocontrol agents for controlling pepper blight. To the best of our knowledge, this paper is the first to provide direct evidence that Trichoderma spp. are capable of killing oospores of $P$. capsici. This study provides a foundation for further investigating the antagonistic effects of Trichoderma spp. on oospores in the soil environment.

\section{Compliance with ethics guidelines}

Heng JIANG, Liang ZHANG, Jing-ze ZHANG, Mohammad Reza OJAGHIAN, and Kevin D. HYDE declare that they have no conflict of interest.

This article does not contain any studies with human or animal subjects performed by any of the authors.

\section{References}

Bell, D.K., Wells, H.D., Markham, C.R., 1982. In vitro antagonism of Trichoderma species against six fungal plant pathogens. Phytopathology, 72(4):379-382. http://dx.doi.org/10.1094/Phyto-72-379

Benhamou, N., Chet, I., 1996. Parasitism of sclerotia of Sclerotium rolfsii by Trichoderma harzianum: ultrastructural and cytochemical aspects of the interaction. Biochem. Cell Biol., 86:405-415.

Benítez, T., Rincón, A.M., Limón, M.C., et al., 2004. Biocontrol mechanisms of Trichoderma strains. Intern. Microbiol., 7:249-260.

Boccas, B.R., 1981. Interspecific crosses between closely related heterothallic Phytophthora species. Phytopathology, 71(1):60-65. http://dx.doi.org/10.1094/Phyto-71-60

Carbone, I., Kohn, L.M., 1999. A method for designing primer sets for speciation studies in filamentous ascomycetes. Mycologia, 91(3):553-556. http://dx.doi.org/10.2307/3761358

Chomnunti, P., Hongsanan, S., Aguirre-Hudson, B., et al., 2014. The sooty moulds. Fungal Divers., 66(1):1-36. http://dx.doi.org/10.1007/s13225-014-0278-5

Do, K.S., Kang, W.S., Park, E.W., 2012. A forecast model for the first occurrence of Phytophthora blight on chili pepper after overwintering. Plant Pathol. J., 28(2):172-184. http://dx.doi.org/10.5423/PPJ.2012.28.2.172

Druzhinina, I.S., Kopchinskiy, A.G., Komoń, M., et al., 2005. An oligonucleotide barcode for species identification in Trichoderma and Hypocrea. Fungal Genet. Biol., 42(10): 813-828.

http://dx.doi.org/10.1016/j.fgb.2005.06.007

Elad, Y., 1988. Ultrastructural scanning electron microscopy study of parasitism of Botrytis cinerea on flowers and fruit of cucumber. Trans. Br. Mycol. Soc., 97(1):185-190. http://dx.doi.org/10.1016/S0007-1536(88)80025-1

Erwin, D.C., Ribeiro, O.K., 1996. Phytophthora Diseases Worldwide. American Phytopathological Society Press, 
St. Paul, MN, p.42-95, 262-268.

Etxeberria, A., Mendarte, S., Larregla, S., 2011. Determination of viability of Phytophthora capsici oospores with the tetrazolium bromide staining test versus a plasmolysis method. Rev. Iberoam. Micol., 28(1):43-49. http://dx.doi.org/10.1016/j.riam.2010.11.005

Ezziyyani, M., Requena, M.E., Egea-Gilabert, C., et al., 2007. Biological control of Phytophthora root rot of pepperchili using Trichoderma harzianum and Streptomyces rochei in combination. J. Phytopathol., 155(6):342-349. http://dx.doi.org/10.1111/j.1439-0434.2007.01237.x

Fry, W.E., Goodwin, S.B., 1997. Resurgence of the Irish potato famine fungus. Bioscience, 47(6):363-371. http://dx.doi.org/10.2307/1313151

Gupta, V.P., Tewari, S.K., Govindaiah, 1999. Ultrastructure of mycoparasitism of Trichoderma, Gliocladium and Laetisaria species on Botryodiplodia theobromae. J. Phytopathol., 147(1):19-24. http://dx.doi.org/10.1046/j.1439-0434.1999.147001019.x

Harman, G.E., 2006. Overview of mechanisms and uses of Trichoderma spp. Phytopathology, 96(2):190-194. http://dx.doi.org/10.1094/PHYTO-96-0190

Hemmes, D.E., Bartnicki-Garcia, S., 1975. Electron microscopy of gametangial interaction and oospore development in Phytophthora capsici. Arch. Microbiol., 103(1):91-112. http://dx.doi.org/10.1007/BF00436336

Hord, M.J., Ristaino, J.B., 1991. Effects of physical and chemical factors on the germination of oospores of Phytophthora capsici in vitro. Phytopathology, 81(12): 1541-1546. http://dx.doi.org/10.1094/Phyto-81-1541

Jaklitsch, W.M., 2009. European species of Hypocrea. Part I. The green-spored species. Stud. Mycol., 63:1-91.

Jaklitsch, W.M., 2011. European species of Hypocrea part II: species with hyaline ascospores. Fungal Divers, 48(1):1-250. http://dx.doi.org/10.1007/s13225-011-0088-y

Kaewchai, S., Soytong, K., Hyde, K.D., 2009. Mycofungicides and fungal biofertilizers. Fungal Divers, 38:25-50.

Kexiang, G., Xiaoguang, L., Yonghong, L., et al., 2002. Potential of Trichoderma harzianum and T. atroviride to control Botryosphaeria berengeriana f. sp. piricola, the cause of apple ring rot. J. Phytopathol., 150(4-5):271-276. http://dx.doi.org/10.1046/j.1439-0434.2002.00754.x

Kopchinskiy, A., Komon, M., Kubice, C.P., et al., 2005. TrichoBLAST: a multilocus database for Trichoderma and Hypocrea identifications. Mycol. Res., 109(06):658-660. http://dx.doi.org/10.1017/S0953756205233397

Kuhajek, J.M., Jeffers, S.N., Slattery, M., et al., 2003. A rapid microbioassay for discovery of novel fungicides for Phytophthora spp. Phytopathology, 93(1):46-53. http://dx.doi.org/10.1094/PHYTO.2003.93.1.46

Kullnig-Gradinger, C.M., Szakacs, G., Kubicek, C.P., 2002. Phylogeny and evolution of the fungal genus Trichoderma: a multigene approach. Mycol. Res., 106(7):757-767. http://dx.doi.org/10.1017/S0953756202006172

Lamour, K.H., Hausbeck, M.K., 2000. Mefenoxam insensitivity and the sexual stage of Phytophthora capsici in Michigan cucurbit fields. Phytopathology, 90(4):396-400.
http://dx.doi.org/10.1094/PHYTO.2000.90.4.396

Liu, L.N., Zhang, J.Z., Xu, T., 2009. Histopathological studies of sclerotia of Rhizoctonia solani parasitized by the EGFP transformant of Trichoderma virens. Lett. Appl. Microbiol., 49(6):745-750. http://dx.doi.org/10.1111/j.1472-765X.2009.02737.x

Liu, Y.J., Whelen, S., Hall, B.D., 1999. Phylogenetic relationships among Ascomycetes: evidence from an RNA polymerase II subunit. Mol. Biol. Evol., 16(12):1799-1808.

McDonald, B.A., Linde, C., 2002. Pathogen population genetics, evolutionary potential, and durable resistance. Annu. Rev. Phytopathol., 40(1):349-379. http://dx.doi.org/10.1146/annurev.phyto.40.120501.101443

Osorio-Hernandez, E., Hernandez-Castillo, F.D., GallegosMorales, G., et al., 2011. In-vitro behavior of Trichoderma spp. against Phytophthora capsici Leonian. Afr. J. Agric. Res., 6(19):4594-4600.

http://dx.doi.org/10.5897/AJAR11.1094

Papavizas, G.C., Bowers, J.H., Johnston, S.A., 1981. Selective isolation of Phytophthora capsici from soils. Phytopathology, 71(2):129-133. http://dx.doi.org/10.1094/Phyto-71-129

Parra, G.P., Ristaino, J.B., 1998. Insensitivity to Ridomil Gold (mefenoxam) found among field isolates of Phytophthora capsici causing Phytophthora blight on bell pepperchilis in North Carolina and New Jersey. Plant Dis., 82(6):711. http://dx.doi.org/10.1094/PDIS.1998.82.6.711D

Pennisi, A.M., Agosteo, G.E., Cacciola, S.O., et al., 1998. Insensitivity to metalaxyl among field isolates of Phytophthora capsici causing root and crown rot of pepperchili in southern Italy. Plant Dis., 82(11):1283. http://dx.doi.org/10.1094/PDIS.1998.82.11.1283A

Qi, R.D., Wang, T., Li, P., et al., 2012. Distribution of mating types of Phytophthora capsici and inheritance in asexual progenies in Anhui Province. Acta Phytopathol. Sin., 42(1):45-50 (in Chinese).

Reino, J.L., Guerrero, R.F., Hernández-Galán, R., et al., 2008. Secondary metabolites from species of the biocontrol agent Trichoderma. Phytochem. Rev., 7(1):89-123. http://dx.doi.org/10.1007/s11101-006-9032-2

Ribeiro, O.K., Erwin, D.C., Zentmyer, G.A., 1975. An improved synthetic medium for oospore production and germination of several Phytophthora species. Mycologia, 67(5):1012-1019. http://dx.doi.org/10.2307/3758592

Satour, M.M., Butler, E.E., 1968. Comparative morphological and physiological studies of the progenies from intraspecific matings of Phytophthora capsici. Phytopathology, 58:183-192.

Sid Ahmed, A., Perez-Sanchez, C., Egea, C., et al., 1999. Evaluation of Trichoderma harzianum for controlling root rot caused by Phytophthora capsici in pepperchili plants. Plant Pathol., 48(1):58-65. http://dx.doi.org/10.1046/j.1365-3059.1999.00317.x

Sid Ahmed, A., Ezziyyani, M., Sánchez, C.P., et al., 2003. Effect of chitin on biological control activity of Bacillus spp. and Trichoderma harzianum against root rot disease in pepper chili (Capsicum annuum) plants. Eur. J. Plant 
Pathol., 109(6):633-637.

http://dx.doi.org/10.1023/A:1024734216814

Thompson, J.D., Gibson, T.J., Plewniak, F., et al., 1997. The Clustal_X windows interface: flexible strategies for multiple sequence alignment aided by quality analysis tools. Nucleic Acid Res., 25(24):4876-4882. http://dx.doi.org/10.1093/nar/25.24.4876

White, T.J., Bruns, T., Lee, S., et al., 1990. Amplification and direct sequencing of fungal ribosomal RNA genes for phylogenetics. In: Innis, M.A., Gelfand, D.H., Sninsky, J.J., et al. (Eds.), PCR Protocols: a Guide to Methods and Applications. Academic Press, New York, USA, p.315-322.

Zhang, J.Z., Li, M.J., 2009. A new species of Bipolaris from the halophyte Sesuvium portulacastrum in Guangdong Province, China. Mycotaxon, 109(1):289-300. http://dx.doi.org/10.5248/109.289

\section{中文概要}

题 目: 体外棘狍木霉与辣椒疫霉菌的拮抗互作

目 的：笁选出对辣椒疫霉菌具有高效拮抗作用的木霉
生防菌株, 研究其对辣椒菌菌丝体和卵孢子的作 用机制, 评价其应用于辣椒疫病的生防潜力。

创新点: 首次在超微结构水平上报道棘狍木霉菌菌丝能重 寄生于辣椒疫霉菌的卵孢子, 为木霉生防菌的应 用提供了科学理论依据。

方 法: 从土壤中分离木霉菌株, 采用对峙培养法篮选木 霉生防菌株。通过形态学和多基因序列 (ITS、tef1 和 $r p b 2$ ）进行鉴定，明确获得木霉菌株的种类。 通过细胞学和超微结构观察, 研究木霉生防菌对 辣椒疫霉菌菌丝和卵孢子的拮抗机制。

结 论: 本研究篎选出了对辣椒疫霉菌菌丝具有高效拮抗 作用的一个木霉菌株（CGMCC 6422），被鉴定 为棘孢木霉菌 (Trichoderma asperellum)。细胞 学和超微结构显示, 该菌株能塌陷辣椒疫霉菌的 菌落, 通过缠绕和穿透辣椒疫霉菌的菌丝体, 引 起菌丝体解体; 首次观察到该菌株能侵染辣椒疫 霉菌的卵孢子, 并引起卵孢子完全降解。综上所 述, 笁选出的木霉生防菌株 CGMCC 6422 具有 应用于防治辣椒疫病的生防潜力。

关键词: 拮抗作用; 电子显微镜; 藏卵器; 卵孢子; 辣椒 